\section{Early precursors of low attention and hyperactivity in moderately and very preterm children at preschool age}

\author{
M. Regina Morales,1,2 Concetta Polizzi,2 \\ Giorgio Sulliotti,1 Claudia Mascolino,2 \\ Giovanna Perricone ${ }^{2}$ \\ 1Ospedali Riuniti - Villa Sofia Cervello \\ Hospital, Palermo; 2Pediatric Psychology \\ Research Unit, Department of \\ Psychology, University of Palermo, Italy
}

\section{Abstract}

The low attention and hyperactivity are major morbidities associated with very and moderately preterm birth. The study has been aimed at investigating the likely occurrence of early precursors of Attention Deficit and Hyperactivity Disorder (ADHD) in very and moderately preterm children at preschool age. The involved children were: 25 very preterm children $(\mathrm{M}=29.4$ weeks of gestational age, $\mathrm{SD}=2)$, with low birth weight $(\mathrm{M}=1200 \mathrm{~g}$, $\mathrm{SD}=250 \mathrm{~g}$ ); 35 moderately preterm children $(\mathrm{M}=34.6$ weeks of gestational age, $\mathrm{SD}=1)$ with low birth weight ( $M=2100 \mathrm{~g}, \mathrm{SD}=250 \mathrm{~g}) ; 60$ healthy full-term children as the control group. Parents of children have been administered specific questionnaires to detect low attention and hyperactivity of their children at home. The data have shown the risk of precursors of ADHD, highlighting statistically significant birth-related differences in both hyperactivity/impulsivity $\left[\mathrm{F}_{(2,119)}=3.5, \mathrm{P}=0.03\right.$, $\left.\eta^{2}=0.06\right]$ and inattention $\left[\mathrm{F}_{(2,119)}=2.4, \mathrm{P}=0.04\right.$, $\eta^{2}=0.04$ ], where very preterm children have got higher scores in these two dimensions compared with full-term and moderately preterm children. The very preterm children have got higher scores of impulsivity and inattention than the full-term children (Tukey'HSD - Honestly Significant Difference; $\mathrm{P}<0.001$ )

\section{Introduction}

Preterm birth, either severe (gestational age $<28$ weeks or low birth weight $<1500 \mathrm{~g}$ ) or moderate (gestational age $<34 / 5$ weeks and weight $<2500 />500 \mathrm{~g}$ ), is a risk condition at cognitive, behavioral and socio-relational levels. ${ }^{1-4}$.

The interruption of the fetal maturation, even when occurs at $32^{\text {nd }}$ or $36^{\text {th }}$ of the gestational week, leads to cerebral immaturity at birth, ${ }^{5-7}$ a risk for the cognitive development of preterm children, ${ }^{8-10}$ as well as attention deficit and hyperactivity disorder (ADHD).11-15

Studies on medium and long-term outcomes have shown that $50-70 \%$ of very low birthweight (VLBW) infants, even in the absence of major disabilities, would display learning difficulties, attention-deficit/hyperactivity disorder, specific neuropsychological deficits, and behavioral problems.11-14 It has been established that VLBW infants are more likely to develop visual perceptual and visual-motor impairments; delay in some of the language functions and working memory deficit. They may also have learning problems and attention deficit at school age. ${ }^{10,16}$

Other studies of the field also have suggested that moderately preterm children (GA $>32 /<35$ weeks) show attention and self-control disorders since preschool age, though at a less severe level when compared with severely preterm cases.1,6-7,16

As an extension of such research projects, this study has been aimed at identifying the presence of early precursors of low attention and hyperactivity (ADHD) in late and very preterm children at preschool age, ${ }^{17}$ characterized by distraction, impulsiveness and hyperactivity within their family environment (home). Therefore, taking in consideration the possible differences due to the gender, it has been verified the presence of statistically significant differences between moderately preterm, very preterm and full-term children at preschool age, with relation to the precursors of ADHD (low attention/distraction, hyperactivity/impulsivity).

The study has provided an innovative contribution with respect to the literature of the field, because it has mainly focused on the precursors of ADHD rather than on its symptoms; it has investigated the precursors of ADHD at preschool rather than at school age. However, the study is an extension of those studies focused on very and moderately preterm children, $, 7,18$ even though they deal with groups of preterm children at school age or adult age.

The study has investigated specific indicators of the precursors of ADHD, identified as inattention meant as distraction during recreational activities and in following instructions to fulfill an activity. A wide literature has shown that preterm children are less capable to focus attention on objects or activities, $9,19,20$ as well as to activate cognitive processes (gathering and selecting information, concentration...) functional for a more rational adjustment to situations. ${ }^{21,22}$

Among these indicators, hyperactivity includes restlessness; difficulties in calm play activities; motor activity modulation disorder with consequential clumsy and uncoordinated movements with a reckless motor behavior. ${ }^{17}$ Motor development impairments occur in very preterm children especially with regard to the capacity of modulation of fine motor skills and
Correspondence: Giovanna Perricone, Pediatric Psychology Research Unit, Department of Psychology, University of Palermo, viale delle Scienze - ed. 15, 90128 Palermo, Italy.

Tel. +39.091.238.97740 - Fax: +39.091.651.3825

E-mail: giovanna.perricone@unipa.it

Key words: precursors, inattention, hyperactivity, preterm children, preschool age.

Acknowledgements: we would like to thank all the parents and children for their participation. The study was conducted in cooperation with the University of Palermo, the V. Cervello Hospital Azienda 0spedaliera 0spedali Riuniti Villa SofiaCervello of Palermo and the infancy schools of Campofelice di Roccella - Lascari. The authors are grateful to all hospital and school staff.

Contributions: MRM, GP, CP, conceived and designed the research project, acquired, analyzed and interpreted the data, wrote the relevant article and critically revised it; GS, interpreted the data and results and shared some reflections concerning the article; $\mathrm{CM}$, administered the instruments to parents and checked their results.

Conflict of interests: the authors declare no potential conflict of interests.

Received for publication: 6 May 2013.

Revision received: 9 October 2013 .

Accepted for publication: 7 November 2013.

This work is licensed under a Creative Commons Attribution NonCommercial 3.0 License (CC BYNC 3.0).

(C) Copyright M.R. Morales et al., 2013

Licensee PAGEPress, Italy

Pediatric Reports 2013; 5:e18

doi:10.4081/pr.2013.e18

visuospatial coordination. ${ }^{23,24}$ Impulsivity is another indicator linked to hyperactivity. It is displayed as behavioral, self-regulation motor skills and self-control impairments. Due to impulsivity, the child has difficulty in respecting the roles, waiting for his/her turn-taking, modulating his/her relationship with the other, intervening in and invading others' activities (plays, conversations, etc.) and s/he is not able to stay still in long waits or postponing gratifications. ${ }^{25}$

\section{Materials and Methods}

\section{Participants}

The research group (Table 1), has been made up of 120 children at the average age of 5 years and 2 months. The children have been selected within some of the local schools and the Neonatal Intensive Care Unit (NICU) of 
the Hospital of Palermo, Italy.

The children collected in the NICU have been very preterm and they were still undergoing the follow-up monitoring of the development trend up to school age, performed by the hospital service. All the children involved have been healthy preterm (i.e. without any neurologic impairments due to cerebral hemorrhage at neonatal phase, nor organic alterations), even though they have been at high risk (GA $<30$ weeks and birth weight $<1500$ g).

The moderately preterm, as well as the fullterm children (i.e. the control group) have been collected in the local schools. They have been chosen by means of a survey on birth carried out in the classroom. The parents of children have been asked to answer some simple questions about the birth of their children (my son was born on...; my son was born in...; my son was born prematurely...; the birth weight of my son was...; my son was hospitalized for...). These information have been compared with those of the discharge report provided by the Neonatology Unit.

Before involving the research group children, the official authorities had approved the proposed path in terms of correctness and ethics. Then the children's parents have been asked to sign the declaration of informed consent according to the Italian Legislative Decree 196/2003 art.13 related to their personal and other people's data protection. Professionals working in the field have followed the official path respecting the criteria that regulate the main codes of ethics of the study, according to a wide research project of the Unit of Research in Pediatric Psychology conducted by the Psychology Department of the University of Palermo.

The involved children have been divided into three groups comparable for socio-cultural features: 25 very preterm children $(\mathrm{M}=29.4$ weeks of gestational age, $\mathrm{SD}=2$ ), with low birth weight $(\mathrm{M}=1200 \mathrm{~g}, \mathrm{SD}=250 \mathrm{~g})$, selected according to the following criteria: gestational age $<32$ weeks, birth weight 1500 to $2500 \mathrm{~g}$; lack of neurologic pathology; sensorial deficit and genetic pathology or malformative syndrome. It has been a small group of preterm children at low risk for adverse cognitive sequelae and it has not displayed any neurological problem during their hospitalization.

Thirty-five moderately preterm children $(\mathrm{M}=34.6$ weeks of gestational age, $\mathrm{SD}=1$ ) without any medical neonatal and/or complications and low birth weight $(\mathrm{M}=2100 \mathrm{~g}, \mathrm{SD}=250$ g), selected according to the following criteria: gestational age $<35$ weeks, birth weight 1500 to $2500 \mathrm{~g}$ without any neurologic pathology, sensorial and genetic pathology deficit, nor malformative syndrome.

Sixty healthy full-term children ( $M=40$ weeks gestational age without any pre- and perinatal complications). The selection criteria of the control group have been: about $40^{\text {th }}$ post-conceptional week at birth (range $=39-41$ gestational weeks); birth weight $>2500 \mathrm{~g}$; lack of pre- and perinatal complications, and lack of neurologic pathology, sensorial deficit and genetic pathology or malformative syndrome.

In relation to the family's socioeconomic status and the socio-family background of the research group (Table 1), the children of the three groups have not differed in a significant way. The groups that have been compared seem to overlap, as shown in certain statistical tests (test $\mathrm{t}, \chi^{2}$ ).

The full term and preterm children belonged to Italian families; $90 \%$ of them have siblings (two children per family on average), whose mother (32 years old on average) belonged to a social middle class (one-income family), with secondary school education on average.

\section{Procedures and instruments}

It has been used a questionnaire to observe the behavior of children at home, the IPDDAG Italian Scale (Attention Deficit Hyperactivity Disorder Early Detection for Parents).26,27 It is a specific questionnaire aimed to the detection of children defined at risk of ADHD during preschool age, performed through the assessment of parents.

In particular, the questionnaire has been administered to the parents of the children. They have been asked to evaluate through a 4response Likert-type scale $(0=$ not at all/never; $1=$ rarely/sometimes; $2=$ quite frequently/most of the time; very frequently/always) how frequently they had observed a particular behavior their children displayed at home.

The questionnaire is made up of 14 items expressed in a negative form, whose odd items refer to inattention, related to the difficulty the child has in prolonging his/her attention on an activity and plays at home, while the even items refer to impulsivity/hyperactivity meant as motor restlessness and self-control and selfregulation disorders. Five more final items have also been to be considered related to risk factors (i.e. forms of socio-cultural disadvantage, poor cognitive potentialities, presence of emotional and/or relational impairments and likely family troubles).

The instrument has been designed by $\mathrm{Re}$ and Cornoldi, according to the Italian normative sample; 26,27 the content of items refers to other previous questionnaires - addressed to parents in order to assess inattention and hyperactivity behavior of children at school

Table 1. Prenatal and family characteristics of the sample by term and preterm birth.

\begin{tabular}{|c|c|c|c|c|c|c|c|c|c|c|}
\hline \multirow[t]{2}{*}{ Variable } & \multicolumn{3}{|c|}{ Very preterm (=25)* } & \multicolumn{3}{|c|}{ Moderately preterm (=35) } & \multicolumn{3}{|c|}{ Full-term $(=60)^{*}$} & \multirow[t]{2}{*}{ P value } \\
\hline & Mean & SD & Range & Mean & SD & Range & Mean & SD & Range & \\
\hline \multicolumn{11}{|c|}{ Clinical characteristics } \\
\hline Gender & \multicolumn{3}{|c|}{$\begin{array}{c}\text { Female: } 15(60 \%) \\
\text { Male: } 10(40 \%)\end{array}$} & \multicolumn{3}{|c|}{$\begin{array}{c}\text { Female: } 15(43 \%) \\
\text { Male: } 20(57 \%)\end{array}$} & \multicolumn{3}{|c|}{$\begin{array}{c}\text { Female: } 35(58 \%) \\
\text { Male: } 25(42 \%)\end{array}$} & \\
\hline Child age (months) & 62 & 3 & $57-67$ & 62 & 4 & $57-67$ & 64 & 2.5 & $61-66$ & n.s. \\
\hline Birth gestational age & 29.4 & 2 & $26-31$ & 34.6 & 1 & $33-35$ & 40 & 2 & $38-42$ & $<0.05$ \\
\hline Birth weight (g) & 1200 & 250 & $950-1450$ & 2100 & 250 & $1950-2350$ & 3200 & 300 & $2900-3500$ & $<0.05$ \\
\hline Days of hospitalization & 80 & 10 & $70-90$ & 15 & 8 & $8-23$ & 2 & 1.5 & $2-3$ & $<0.05$ \\
\hline \multicolumn{11}{|c|}{ Family's background characteristics } \\
\hline Household income & 1 & 1 & $1-2$ & 1 & 1 & $1-2$ & 1 & 1 & $1-2$ & n.s. \\
\hline Number of working parents & 1 & 1 & $1-2$ & 1 & 1 & $1-2$ & 1 & 1 & $1-2$ & n.s. \\
\hline Education level of mother (years) & 13 & 8 & $8-23$ & 12 & 8 & $8-22$ & 12 & 8 & $8-22$ & n.s. \\
\hline Mother's age (years) & 31.6 & 6 & $24-37$ & 32.6 & 5 & $26-38$ & 29.6 & 5 & $24-34$ & n.s. \\
\hline Number of children & 2 & 1.5 & $1-3$ & 2 & 1.5 & $1-4$ & 2 & 1.5 & $1-4$ & n.s. \\
\hline
\end{tabular}

*Healthy Preterm (HPT): no medical/neurological complications. 
age, DSM-IV criteria and Kendall and Wilcox's Scale. The validity of the scale has been verified through a factorial analysis whose results show that the division of items in components (inattention and hyperactivity) have been realized. The values of Pearson's coefficients of correlation and Cronbach's alpha value have shown a good internal coherence of the instrument. The predictive quality of the instrument has been very good.

The higher the score, the larger the presence of patognomonic tracts of the disorder has been.

This questionnaire allows to detect children at risk of attention difficulties and hyperactivity on the basis of the score in the sub-scale; with regard to reading and interpreting the result, a score equal to or more than 14 (cut-off score) shows the presence of a likely risk of ADHD at preschool age (impulsivity/hyperactivity scale: mean score $=13.70, \mathrm{SD}=4.30$; inat tention scale: mean score $=11.70, \mathrm{SD}=3.80$ ).

\section{Results}

\section{Data treatment and analysis}

The statistic program for Social Sciences SPSS 16 has been used to analyze the data.

The Kolmogorov-Smirnov's test has been used to verify the presence of a normal distribution of the scores obtained for each of the two scales of the IPDDAG $(P>0.05)$ and the Levene's test has been used to verify the equality of variances in the three samples (homogeneity of variance) $(\mathrm{P}>0.05)$. Then, a multivaried covariance (MANCOVA) with continuous variables (scores related to the two scales) 3 (birth) X 2 (gender) has been used, and birth weight has been analyzed as the covariate variable. The likely differences between the scores of the two scales (dependent variables) have been analyzed considering birth (Term/Very and Moderately Preterm) and gender (F/M) as independent variables, and the birth weight as covariate variable. A value of $\mathrm{P}<0.05$ has been considered significant.

A post-hoc test (Tukey'HSD - Honestly Significant Difference) has been used in order to determine which groups (full term, late preterm and very preterm children) has differed from each other. The $\chi^{2}$ test has been used to calculate the significance of the number of children (frequencies) of each group, who has exceeded the cut-off score of the instrument (number of children with lower than, equal to or higher than the cut-off).

The results of the multivariate analysis have only showed significant effects of the birth (Wilks' $\lambda=0.93, \quad \mathrm{~F}_{(4,119)}=1.81, \quad \mathrm{P}=0.048$, $\left.\eta^{2}=0.32\right)$.

There have not been statistically significant effects related to the variables birth weight (Wilks' $\lambda=0.99, \quad \mathrm{~F}_{(2,119)}=0.032, \quad \mathrm{P}=0.13$, $\eta^{2}=0.001$ ), gender (Wilks' $\lambda=0.91$, $\left.\mathrm{F}_{(2,119)}=5.11, \mathrm{P}=0.13, \eta^{2}=0.032\right)$ and birth $X$ gender (Wilks' $\lambda=0.96, \mathrm{~F}_{(4,119)}=1.08, \mathrm{P}=0.36$, $\left.\eta^{2}=0.02\right)$. The children of the research group have got indifferently high scores of inattention and hyperactivity, whatever their gender and birth weight has been. The period of gestation, conversely, has seemed to be the sole variable that has significantly affected the attention and hyperactivity field.

The preterm and full-term children have differed with relation to the presence of low attention and hyperactivity/impulsivity; the parents have shown statistically significant differences related to preterm birth in both hyperactivity/impulsivity $\left[\mathrm{F}_{(2,119)}=3.5, \mathrm{P}=0.03\right.$, $\left.\eta^{2}=0.06\right]$ and inattention $\left[\mathrm{F}_{(2,119)}=2.4, \mathrm{P}=0.04\right.$, $\eta^{2}=0.04$ ], where the very preterm children have got higher scores in these two dimensions compared to the full-term and late preterm children (Table 2). The parents have reported a description of preterm children' behavior as children who, regardless of their gender, not only had shown attention deficit at home, but they had also shown restlessness, excessive movements, difficulties in modulating motor skills activities with clumsy uncoordinated reckless and not aimed movements.

The children's scores also have differed depending on preterm or full-term birth: the very and moderately preterm children at preschool age have shown higher scores of impulsivity than full-term children (Tukey'HSD $\mathrm{P}<0.001$ ); the very and moderately preterm children have also shown higher scores of inattention than full-term children (Tukey'HSD $\mathrm{P}<0.001$ ). The very and moderately preterm children have not differed in relation to impulsivity and inattention (Table 3).

In relation to such data, from a solely descriptive point of view, it has to be considered the relevance of the frequencies of preterm children with regard to the scores of hyperactivity and inattention precursors since they are close to the cut off score fixed in the questionnaire. $20 \%$ of the moderately preterm children (no. 7) and $20 \%$ of the very preterm children (no. 5) exceed the cut-off score being at risk of inattention, and $20 \%$ of them is on the edge (no. 5/7); only $10 \%$ of the full term children (no. 6) would seem to be at risk and $5 \%$ of them is on the edge (no. 3). A large number of children with low attention $\left(\chi^{2}=6.6\right.$, $\mathrm{gf}=2, \mathrm{P}=0.03$ ) have been identified.

With regards to hyperactivity/impulsivity, $20 \%$ of the moderately preterm children (no. 7) and $40 \%$ of the very preterm children (no. 10) would seem to be at risk and $20 \%$ is on the edge (no. 5/7); $20 \%$ of the full-term children are at risk (no. 12) and 5\% of them are on the edge (no. 3). Even in this case, the number of preterm children displaying precursors of hyperactivity, appears statistically higher compared to the group of full-term children $\left(\chi^{2}=17.7, \mathrm{gf}=2, \mathrm{P}=0.001\right)$.

Table 2. Precursors of attention deficit and hyperactivity/impulsivity in research group.

\begin{tabular}{|c|c|c|c|c|c|c|c|c|c|c|c|c|}
\hline $\begin{array}{l}\text { Scales } \\
\text { IPDDAG }\end{array}$ & $\begin{array}{l}\text { Mean } \\
\text { (SD) }\end{array}$ & $\begin{array}{l}\text { Very } \\
\text { preterm } \\
\text { children } \\
\text { Mean } \\
\text { female } \\
\text { (SD) }\end{array}$ & $\begin{array}{l}\text { Mean } \\
\text { male } \\
\text { (SD) }\end{array}$ & $\begin{array}{l}\text { Mean } \\
\text { (SD) }\end{array}$ & $\begin{array}{l}\text { Voderately } \\
\text { preterm } \\
\text { children } \\
\text { Mean } \\
\text { female } \\
\text { (SD) }\end{array}$ & $\begin{array}{l}\text { Mean } \\
\text { male } \\
\text { (SD) }\end{array}$ & $\begin{array}{l}\text { Mean } \\
\text { (SD) }\end{array}$ & $\begin{array}{l}\text { Term } \\
\text { children } \\
\text { Mean } \\
\text { female } \\
\text { (SD) }\end{array}$ & $\begin{array}{l}\text { Mean } \\
\text { male } \\
(\mathrm{SD})\end{array}$ & $\begin{array}{c}\text { Birth } \\
\text { (VP/MPT/T) }\end{array}$ & $\begin{array}{c}\text { Gender } \\
\text { (M/F) }\end{array}$ & $\begin{array}{l}\text { Gender } \\
\text { birth }\end{array}$ \\
\hline Inat & $9.2(7.5)$ & $10.1(9)$ & $7.1(4.1)$ & $8.9(4.9)$ & $8.8(5.7)$ & $8.9(4.4)$ & $5.4(4)$ & $6(4.6)$ & $4.4(2.3)$ & $\begin{array}{c}\mathrm{F}_{(2,119)} 2.4 \\
\text { sign. }<0.05 \\
\eta^{2} 0.04\end{array}$ & $\begin{array}{c}\mathrm{F}_{(1,119)} 2.5 \\
\text { n.S. } \\
\eta^{2} 0.02\end{array}$ & $\begin{array}{c}\mathrm{F}_{(2,119) .} .9 \\
\text { n.s. } \\
\eta^{2} 0.02\end{array}$ \\
\hline Hyp/Imp & $12.5(7.4)$ & $12.3(7.8)$ & $12.8(7)$ & $11.9(4.6)$ & $10.6(4.2)$ & $13.2(4.3)$ & $8(2.5)$ & $7.9(2.6)$ & $8.1(2.4)$ & $\begin{array}{c}\mathrm{F}_{(2,119)} 3.5 \\
\text { sign. }<0.05 \\
\eta^{2} 0.06\end{array}$ & $\begin{array}{c}\mathrm{F}_{(1,119)} 1.4 \\
\text { n.S. } \\
\eta^{2} 0.01\end{array}$ & $\begin{array}{c}\mathrm{F}_{(2,119)} 1.8 \\
\text { n.s. } \\
\eta^{2} 0.03\end{array}$ \\
\hline
\end{tabular}

IPDDAG, attention deficit hyperactivity disorder early detection for parents; SD, standard deviation; VP, very preterm; MPT, moderately preterm; T, term; Inat, inattention; Hyp/lmp, hyperactivity/impulsivity. 


\section{Discussion and Conclusions}

The purpose of this study has been to explore the relation between preterm birth and the outcome at age 5 in preterm children at low risk of adverse sequelae. As it has been hypothesized, and like other studies have shown, ${ }^{28-30}$ low attention and hyperactivity have been displayed by preterm children at preschool age.

The main results of the study have shown the presence of a profile of preterm children who, even at preschool age, are at risk of precursors of attention deficit and hyperactivity disorder. The preterm children of the present experimental group, especially the very preterm, have been reported as being hyperactive and restless children at home, showing difficulties in self-regulating and self-controlling during calm play activities.

The relevance of some data of the research lies on the lack of significant effects linked to gender and birth-weight, unlikely other contributions of the field. ${ }^{20-31}$ It would seem that being male or female is not a risk factor of attention disorder and hyperactivity for the children involved in the research, even though male children have shown higher tendency to be more hyperactive and distracted than female, as it has been also reported by a wide literature of the field and early studies. ${ }^{31}$

These conclusions must be tempered by the fact that the children have been evaluated for ADHD symptoms, not for a clinical diagnosis of ADHD. Although prematurity, perinatal morbidity, and toddlerhood neurological and medical health status predict these symptoms at age 4 , additional work is needed to make these connections to the clinical diagnosis of ADHD at a later age.

The different percentage of the children who are at risk of precursors of ADHD at preschool age, for having exceeded the cut-off score of the instrument, is another important outcome. The neonatal clinic history of the children involved has not been characterized by any cerebral hemorrhage, nor by neurologic sequelae. During their hospitalization at the NICU not any severe hypoglycaemic shock occurred, nor long periods of supplemental oxygenation (intubation) were necessary. That underlines the individual valence of the developmental path of each child and of the reference family environment that, although it has been little detected by the analyses performed by this study, has not been characterized by any psychosocial risk factors (i.e. smoking during pregnancy; use/abuse of substances; risk factors due to psychiatric or relational pathologies, etc.). ${ }^{32-34}$

Such data trace a similarity between the maturative and developmental path of the severely preterm children ( $<32$ weeks) and that of the moderately preterm highlighting, ${ }^{6}$ even in the latter case, likely risks linked to moderately preterm birth. Such data comply with those studies that have shown that severe and moderate prematurity is a factor that may affect the development of impulsivity regulation, ${ }^{6,11}$ self-regulation and behavior and motor self-control processes (as well as concentration and attention skills).

The levels of maturity of the physiological brain processes of fetus reached before their interruption caused by birth at 34 weeks are important too, ${ }^{6}$ because together with the genetic and environmental factors (i.e. early interaction with hospital environment, medical treatments, relationships with parents, external stimuli, etc.), contribute to trace problems and slight disorders only occurring in terms of slowness and/or difficulty at preschool and school age.

These data establish an initial level of behavior in the children of the research group, which can potentially lead to precursors of school-age deficit and/or hyperactivity disorder. By comparing the data of the follow-up after two years, it is possible to check the stability or the change in trend.

\section{Clinical implications}

Due to the increasing survival rate of preterm infants, the impact of perinatal morbidities and their relationship to low attention and hyperactivity pose an important developmental question: are the preterm children with high neonatal risk who display low attention and high activity at age 5, at an increased risk of developing ADHD?

Further longitudinal studies are needed using diagnostic measures to answer this question.

However, the results should not make the moderately preterm child's development pathological, nor make it always requiring medicalization.

The study suggests the need of hypothesizing, not only in the case of severe prematurity, specific paths of assessment of the various evolutional dimensions of children aimed at monitoring certain aspects of their cognitive, motor, socio-relational and behavioral development. The assessment and screening up to school age are aimed at an early identification of problematic areas of attention and self-regulation.

The study claims the need to activate a follow-up of the preterm children and a developmental monitoring, performed by pediatricians through developmental scales such as the Griffith's Mental Development Scales. ${ }^{35}$

The study also provides some hints for prevention of $\mathrm{ADHD}$ risk in preterm children. Early training courses should be addressed to preschool children to help them develop selfregulation skills (i.e. emotional, cognitive, relational and behavioral). Such courses should also be addressed to parents in order to help them develop their parental competencies, useful for facing behavioral problems related to everyday life.

\section{Limits of the study}

Some final considerations about the limits of this study have to be made. One of the lim-

Table 3. Differences between groups for birth (full term, moderately preterm, very preterm): Tukey's HSD Test (Honestly Significant Difference).

\begin{tabular}{|c|c|c|c|c|c|}
\hline Variable & Birth (I) & Birth (J) & Differences between means (I-J) & Std. error & P value \\
\hline Hyperactivity/impulsivity & $\begin{array}{c}\text { Full term } \\
\text { Moderately preterm } \\
\text { Very preterm }\end{array}$ & $\begin{array}{l}\text { Moderately preterm } \\
\text { Very preterm } \\
\text { Full term } \\
\text { Very preterm } \\
\text { Full term } \\
\text { Moderately preterm }\end{array}$ & $\begin{array}{l}-4.17 \\
-4.65 \\
4.17 \\
-0.48 \\
4.65 \\
0.48\end{array}$ & $\begin{array}{l}1.09 \\
0.98 \\
1.09 \\
1.19 \\
0.98 \\
1.19\end{array}$ & $\begin{array}{c}0.001 \\
0.001 \\
0.001 \\
\text { n.s. } \\
0.001 \\
\text { n.s. }\end{array}$ \\
\hline Inattention & $\begin{array}{c}\text { Full term } \\
\text { Moderately preterm } \\
\text { Very preterm }\end{array}$ & $\begin{array}{l}\text { Moderately preterm } \\
\text { Very preterm } \\
\text { Full term } \\
\text { Very preterm } \\
\text { Full term } \\
\text { Moderately preterm }\end{array}$ & $\begin{array}{l}-3.83 \\
-3.54 \\
3.83 \\
0.28 \\
3.54 \\
-0.28\end{array}$ & $\begin{array}{l}1.24 \\
1.11 \\
1.24 \\
1.35 \\
1.11 \\
1.35\end{array}$ & $\begin{array}{c}0.007 \\
0.005 \\
0.007 \\
\text { n.s. } \\
0.005 \\
\text { n.s. }\end{array}$ \\
\hline
\end{tabular}


its can be the little number of participants, drawing conclusions that cannot be generalized, highlighting possible affections of the development of the moderately and very preterm children. Furthermore, the composition of the sample size of this research project does not include children with important cognitive sequelae, enhancing the chance of spurious findings, or minimally that the magnitude of the observed relations will not be as high when a larger sample is studied. These considerations suggest the importance of other studies on preterm infants who had cerebral palsy to better understand their developmental trend. This is the only way to explore the predictive value of the different variables.

Another limit could be the use of the heteroassessment tool administered to the parents to observe behavior ascribable to precursors of inattention and hyperactivity disorder in their children.

This study is part of a longitudinal researchintervention that has engendered attention, in parents and teachers, towards preterm birth so far little considered.

\section{References}

1. Huddy CLJ, Johnson A, Hope PL. Educational and behavioral problems in babies of 32-35 weeks gestation. Arch Dis Child Fetal Neonatal Ed 2001;85:F23-8.

2. Bhutta AT, Cleves MA, Casey PH, et al. Cognitive and behavioral outcomes of school-aged children who were born preterm: a meta-analysis. JAMA 2002; 288:728-37.

3. Aylward GP. Neurodevelopmental outcomes of infants born prematurely. J Dev Behav Pediatr 2005;26:427-40.

4. McGrath MM, Sullivan MC. Neonatal morbidities and cumulative risk and school age outcomes. Compr Issues Pediatr Nurs 2002;45:104-12.

5. Inder TE, Warfield SK, Wang $\mathrm{H}$, et al. Abnormal cerebral structure is present at term in premature infants. Pediatrics 2005;115:286-94.

6. van Baar AL, Vermaas J, Knots E, et al. Functioning at school age of moderately preterm children born at 32 to 36 weeks' gestational age. Pediatrics 2009;124:251-7.

7. Heinonen K, Räikkönen K, Pesonen Anu$\mathrm{K}$, et al. Behavioural symptoms of attention deficit/hyperactivity disorder in preterm and term children born small and appropriate for gestational age: a longitudinal study. Pediatrics 2010;10:91.

8. Kinney HC. The near-term (late preterm) human brain and risk for periventricular leukomalacia: a review. Semin Perinatol
2006;30:81-8.

9. Espy KA, Senn TE, Charack DA, et al. Perinatal $\mathrm{pH}$ and neuropsychological outcomes at age 3 years in children born preterm: an exploratory study. Dev Neuropsychol 2007;32:669-82.

10. Peterson BS, Anderson AW, Ehrenkranz R, et al. Regional brain volumes and their later neurodevelopmental correlates in term and preterm infants. Pediatrics 2003;111:939-48.

11. Strang-Karlsson S, Raikkonen K, Pesonen AK, et al. Very low birth weight and behavioral symptoms of attention deficit hyperactivity disorder in young adulthood: the Helsinki study of very-low-birth-weight adults. Am J Psychiatry 2008;165:1345-53.

12. Hille ET, den Ouden AL, Saigal S, et al. Behavioural problems in children who weigh $1000 \mathrm{~g}$ or less at birth in four countries. Lancet 2001;357:1641-3.

13. Hack M, Youngstrom EA, Cartar L, et al. Behavioral outcomes and evidence of psychopathology among very low birth weight infants at age 20 years. Pediatrics 2004;114:932-40.

14. Jennische M, Sedin G. Linguistic skills at 6 $1 / 2$ years of age in children who required neonatal intensive care in 1986-1989. Acta Paediatrica 2001;90:199-212.

15. Krain AL, Castellanos FX. Brain development and ADHD. Clin Psychol Rev 2006;26:433-44.

16. Chyi LJ, Lee HC, Hintz SR, et al. School outcomes of late preterm infants: special needs and challenges for infants born at 32 to 36 weeks gestation. J Pediatr 2008;153:25-31.

17. Byrne SM, Bawden HN, Beattie TL, De Wolfe NA. Preschoolers classified as having attention-deficit hyperactivity disorder (ADHD): DSM-IV symptom endorsement patterns. J Child Neurol 2000;15:533-8.

18. Lindström K, Lindblad F, Hjern A. Preterm birth and attention-deficit/hyperactivity disorder in schoolchildren. Pediatrics 2011;127:858-65.

19. Gillberg C. Deficits in attention, motor control, and perception: a brief review. Arch Dis Childhood 2003;88:904-10.

20. McGrath MM, Sullivan M, Devin J, et al. Early precursors of low attention and hyperactivity in a preterm sample at age four. Issues Compr Pediatr Nurs 2005;28:115.

21. Lawson KR, Ruff HA. Early focused attention predicts outcome for children born prematurely. J Dev Behav Pediatr 2004;25: 399-406.

22. Shum D, Neulinger K, O'Callaghan M, Mohay H. Attentional problems in children born very preterm or with extremely low birth weight at 7-9 years. Arch Clin Neuropsychol 2008;23:103-12.
23. Foulder-Hughes LA, Cooke RW. Motor, cognitive, and behavioural disorders in children born very preterm. Dev Med Child Neurol 2003;45:97-103.

24. Hemgren E, Persson K. Associations of motor co-ordination and attention with motor-perceptual development in 3-yearold preterm and full-term children who needed neonatal intensive care. Child Care Health Dev 2007;33:11-21.

25. Clark CA, Woodward LJ, Horwood LJ, Moor S. Development of emotional and behavioral regulation in children born extremely preterm and very preterm: biological and social influences. Child Dev 2008;79:144462.

26. Riello M, Re AM, Cornoldi C. Costruzione di uno strumento rivolto alla famiglia per l'identificazione precoce del DDAI. Disturbi di attenzione e iperattività 2005; 1:9-26.

27. Re AM, Cornoldi C. Two new rating scales for assessment of ADHD symptoms in Italian preschool children. A comparison between parent and teacher ratings. $\mathrm{J}$ Atten Disord 2009;12:532-9.

28. Perricone G, Morales MR. Prerequisiti e indicatori di difficoltà di apprendimento in bambini moderatamente pretermine di età prescolare, Ricerche di Psicologia 2011;1:23-38.

29. Perricone G, Morales MR. The temperament of preterm children in preschool age. It J Pediatr 2011;37:4.

30. Perricone G, Morales MR, Polizzi C. Developmental outcomes of preterm birth: cognitive and behavioural problems in moderately preterm children at preschool age. In: Contreiras D, Sampaio J, eds. Preterm Infants. Development, prognosis and potential complications. New York: Nova Science Publishers; 2012. pp 167194.

31. Reiss AL, Kesler SR, Vohr B, et al. Sex differences in cerebral volumes of 8-year-olds born preterm. J Pediatr 2004;145:242-9.

32. Perricone G, Prista Guerra M, Cruz 0, et al. Maternal coping strategies in response to a child's chronic and oncological disease: a cross-cultural study in Italy and Portugal. Pediatr Rep 2013;5:e11.

33. Perricone G, Morales MR, Anzalone G. School readiness of moderately preterm children at preschool age. Eur J Psychol Educ 2012;1-11.

34. Perricone G, Morales MR, Anzalone G. Neurodevelopmental outcomes of moderately preterm birth: precursors of attention deficit hyperactivity disorder at preschool age. SpringerPlus 2013;2:221.

35. Griffith R. GMDS-ER Griffiths mental development scales - extended revised. Firenze: 0.S. Giunti; 2006. 